\title{
Iron-supplementation and diarrhoea from the perspective of groundwater iron
}

Sabuktagin Rahman ${ }^{1 *}$ M.B.B.S., M.Sc., M.F.S.N.; Santhia Ireen² M.Sc., M.Phil., Ph.D.

1Public Health, School of Medicine, Griffith University, Gold Coast Campus, QLD 4222, Australia

2Alive and Thrive Bangladesh, Genetic Baro Bhuiyan, Kemal Ataturk Avenue, Gulshan 2, Dhaka-1212, Bangladesh

*Corresponding author.

E-mail: sabuktagin.rahman@griffithuni.edu.au;

Phone: +61 481873612

Conflicts of interest: The authors declare no competing interests.

Supplementation of iron - alone or in combination with other nutrients (e.g. Micronutrient Powder, MNP)--is a well-known preventive measure for controlling iron deficiency anaemia in children of the middle-and low-income countries, where the burden of the condition is high (DeRegil et al, 2013; De-Regil et al, 2011). However, there is good documentation that such supplementation is associated with occasional side-effects, e.g. diarrhoea, bloody diarrhoea, loose stools, nausea, vomiting, fever etc. (Soofi et al, 2013; Salam et al, 2013; Zlotkin et al, 2013). Iron, in a free, unbound state, is a pro-oxidant in the body having the potential to inflict damaging effects (Scholl et al, 2005). Hence, its entry into the body is tightly regulated. This regulation is informed partly by the status of the iron reserve in the body (Rishi et al, 2015; Saito et al, 2014).

Groundwater iron is a recognized determinant of population level anaemia. Groundwater is the principal source of potable water in Bangladesh (British Geological Survey, 2001) and many countries in Asia and Latin America (Graaf et al, 2016). In this letter, we attempt to explain the interaction of iron supplementation and its side-effects (e.g. diarrhoea) in rural Bangladeshi children and women from the perspective of groundwater iron, drawing on the findings of a recent trial entitled, "Effect of Multiple Micronutrient Powder (MNP) and anthelmintics on morbidity and nutritional status of extremely poor women and children: A cluster randomised trial in North West Bangladesh” published in World Nutrition (Rana et al, 2019). That trial was nested within a program targeted to improve livelihoods and poverty among impoverished women and children of a rural setting in Bangladesh. The intervention arm received nutritionspecific interventions for the recruited children ( $>6$ mo $<5$ years) and non-pregnant women 
(>15 years), intended mainly to control anaemia. It was a 15-component MNP containing $10 \mathrm{mg}$ iron/sachet (1 sachet every day to be consumed for 12 months). The intervention further included provision of biannual anti-helminth medication and flip-flop shoes. The control arm subjects received no nutrition-specific intervention. All the subjects received nutrition-sensitive interventions pertaining to livelihoods (Rana et al, 2019).

The authors of the trial reported that the prevalence of diarrhoea decreased in women and children during the trial period, but there was no statistically significant difference between the intervention and control groups. The authors did not report longitudinal changes of diarrhoea prevalence in the comparison groups. We tried to assess this from the reported results of prevalence data; and calculated for the children that the absolute longitudinal decrease (from baseline to end line) of prevalence of diarrhoea over the preceding 30 days was $41.6 \%$ and $16.9 \%$ in the intervention and the control groups respectively. In women, the longitudinal decrease of absolute prevalence of diarrhoea was $28.5 \%$ and $20.8 \%$ respectively in the intervention and control groups. The above estimates show that the decrease was more pronounced in the intervention children compared with the intervention women.

The differential rates of decline of the prevalence of diarrhoea between the intervention children and women warrant a discussion on the physiological regulation of absorption of iron. Absorption of intestinal iron is inhibited by hepcidin, which is activated when the reserve of body iron (e.g. infection-adjusted ferritin level and/or iron level) is maintained at a satisfactory level, or when an infection is introduced to the body. These circumstances require a limit to the absorption of exogenous extracellular iron into the body (Saito 2014), which might be otherwise counterproductive. The iron content in groundwater in Bangladesh is high in many parts of the country (British Geological Survey, 2001) but low in others. A high level of iron in drinking groundwater source is positively associated with iron status in children and women (National Micronutrient Status Survey, 2011-12; Rahman et al, 2016). Ingestion of iron from groundwater might build up a good iron status in the body, which according to the physiologic regulation might exert some inhibition to further iron absorption. This natural iron, when added to by the supplemental iron (e.g. under anaemia control program) may remain unabsorbed in large amount; and plausibly builds up in the large intestines, with increased likelihood of side-effects mediated through adversaries on gut microbiota (Zimmermann et al, 2010; Jaeggi et al, 2015). To complement the above postulation, recently, a randomized controlled trial on the efficacy of an MNP with a low dose of iron in rural Bangladeshi children drinking groundwater with a high level of iron (Fe in groundwater $\geq 2 \mathrm{mg} / \mathrm{L}$ ) showed that the low-iron formulation (containing 5 $\mathrm{mg}$ iron) resulted in lower incidence of the iron-induced side effects, including diarrhoea, nausea and fever, compared to the children who received the standard MNP (containing $12.5 \mathrm{mg}$ iron) (Rahman et al, 2019).

The preceding discussion on iron metabolism, iron-supplementation induced side-effects, and the perspective of groundwater iron in Bangladesh may explain the reason for the differential rate of decrease of the prevalence of diarrhoea between the children and women over the course of the 
Rana et al. trial. The site of the trial was Bogura (formerly Bogra) District which has a predominantly low level of iron in groundwater. According to the data of the British Geological Survey, 2001, the majority of the Bogura water samples had iron concentration $<1 \mathrm{mg} / \mathrm{L}$ with many samples close to zero. Young children drink a much lower quantity of drinking water than adult women. Though the trial did not record the amount of water consumed, nor estimated the concentration of iron in water, their intakes in this climate might be consistent with $\sim 800 \mathrm{ml} /$ day in children aged 2-5 years (Rahman et al, 2019); and 2.7 L/day in adult non-pregnant women (Merrill et al, 2011). This implies that at a given concentration of iron in groundwater, the underfive children would receive 3-3.5 times less iron from drinking water than the adult women. Therefore, in the setting of the trial (Rana et al; 2019) with predominantly a low concentration of iron in drinking groundwater, children's intake of iron from groundwater could be plausibly low, and consequently their reserve of the body iron was unlikely to be adequate. Hence, according to the hepcidin-based metabolism, there was a demand for the supplemental iron from the MNPs. This was reflected in an efficient change in haemoglobin concentration from baseline to end line (improvement of $7.8 \mathrm{~g} / \mathrm{L}$ compared to control).

For women we assume that, due to a higher intake of groundwater iron (resulting from much higher amount of water-drinking), their reserve of body iron plausibly could be better than that in the children. However, due to the physiological demand (i.e. for losses in menstruation in nonpregnant women), they are likely to be in the state of demand for iron and, thus also responded to the MNP treatment (marked a $4.8 \mathrm{~g} / \mathrm{L}$ increment of haemoglobin compared to the control group).

Both the children and women in the trial received an equal amount of supplemental iron (10 mg/day) from MNPs. Then the assumed lower amount of iron consumed from groundwater rendered the children a lower amount of the aggregate iron (Supplemental iron + groundwater iron) than the women. This implies that, there was the inflow of iron into the body following the active demand in both the populations; however, the amount of unabsorbed iron in the intestines was conceivably less in the children over the intervention time. This lower amount of unabsorbed iron means presumably lesser adversaries on intestinal microbiome (Zimmermann et al, 2010; Jaeggi et al, 2015), which was consistent with more pronounced longitudinal (baseline to end line) decrease of diarrheal prevalence in the children compared to the women. Had the trial been conducted in a setting with a high concentration of iron in drinking groundwater, perhaps a different profile of diarrhoea prevalence (presumably, a persistently high prevalence) in the intervention subjects over the study time might have been reported.

In conclusion, in the traditional understanding of interaction between iron supplementation and side-effects, groundwater iron may add an additional layer for explanation. Knowledge of background level of groundwater iron in the communities which use groundwater as potable water; and assessment of intake of groundwater iron is important for the iron/MNP supplementation interventions for proper evaluation of morbidities. Such an evaluation of gastrointestinal morbidities may help the subsequent adjustment of the design of the supplementation projects in settings with varied groundwater iron levels. 


\section{References}

1. De-Regil LM, Suchdev PS, Vist GE, Walleser S, \& Peña-Rosas JP (2013). Home fortification of foods with multiple micronutrient powders for health and nutrition in children under two years of age (Review). Evid Based Child Health, 8(1):112-201. doi: 10.1002/ebch.1895.

2. De-Regil LM, Jefferds ME, Sylvetsky AC \& Dowswell T (2011). Intermittent iron supplementation for improving nutrition and development in children under 12 years of age. Cochrane Database Syst Rev, 12:CD009085. doi: 10.1002/14651858.CD009085.pub2.

3. Soofi S, Cousens S, Iqbal SP, Akhund T, Khan J, Ahmed I, Zaidi AK, Bhutta ZA (2013). Effect of provision of daily zinc and iron with several micronutrients on growth and morbidity among young children in Pakistan: A cluster-randomised trial. Lancet, 382, 29-40.

4. Salam RA, MacPhail C, Das JK, Bhutta ZA (2013). Effectiveness of Micronutrient Powders (MNP) in women and children. BMC Public Health, 13, S22.

5. Zlotkin S, Newton S, Aimone AM, Azindow I, Amenga-Etego S, Tchum K, Mahama E, Thorpe KE, Owusu-Agyei S (2013). Effect of iron fortification on malaria incidence in infants and young children in Ghana: A randomized trial. JAMA, 310, 938-947.

6. Scholl TO (2005). Iron status during pregnancy: Setting the stage for mother and infant. Am J Clin Nutr, 81, 1218S-1222S.

7. Rishi G, Wallace DF, Subramaniam VN (2015). Hepcidin: Regulation of the master iron regulator. Biosci Rep, 35, 1-12.

8. Saito, H (2014). Metabolism of iron stores. Nagoya J Med Sci, 76, 235-254

9. British Geological Survey \& Department for Public Health Engineering, Government of the People's Republic of Bangladesh. Arsenic Contamination of Groundwater in Bangladesh; BGS Technical Report, WC/00/19; Kinniburgh, D.G., Smedley, P.L., Eds.; BGS: Keyworth, UK, 2001.

10. Graaf ID, EGU Blog. Available online: https://blogs.egu.eu/network/waterunderground/2016/12/20/limits-to-global-groundwater-use/

11. Rana MM, Schellenberg J (2019). Effect of Multiple Micronutrient Powder (MNP) and Anthelmintics on morbidity and nutritional status of extremely poor women and children: A cluster randomised trial in NorthWest Bangladesh. World Nutrition (10):43-6. DOI: https://doi.org/10.26596/wn.201910443-62 
12. National Micronutrient Survey 2011-12; Final Report; Institute of Public Health Nutrition, United Nation Children's Fund (UNICEF), ICDDR,B and Global Alliance for Improved Nutrition (GAIN): Dhaka, Bangladesh, 2013.

13. Rahman S, Ahmed T, Rahman AS, Alam N, Ahmed AMS, Ireen S, Chowdhury IA, Rahman SMM, 2016. Determinants of iron status and $\mathrm{Hb}$ in the Bangladesh population: The role of groundwater iron. Public Health Nutr, 19, 1862-187.

14. Zimmermann MB, Chassard C, Rohner F et al. (2010). The effects of iron fortification on the gut microbiota in African children: a randomized controlled trial in Cote d'Ivoire. Am J Clin Nutr, 92, 1406-1415

15. Jaeggi T, Kortman GA, Moretti D, Chassard C,Holding P, Dostal A....\&Zimmermann $\mathrm{MB}(2015)$. Iron fortification adversely affects the gut microbiome, increases pathogen abundance and induces intestinal inflammation in Kenyan infants. Gut, 64(5):731-42. doi: 10.1136/gutjnl-2014-307720

16. Rahman S, Lee P, Raqib R, Roy AK, Khan MR, Ahmed F, 2019. Effect of Micronutrient Powder (MNP) with a Low-Dose of Iron on Hemoglobin and Iron Biomarkers, and Its Effect on Morbidities in Rural Bangladeshi Children Drinking Groundwater with a High-Level of Iron: A Randomized Controlled Trial. Nutrients, 11, 2756.

17. Merrill, R.D.; Shamim, A.S.; Ali, H.; Jahan, N.; Labrique, A.B.; Schulze, K.; Christian, P.; West, K.P., Jr (2011). Iron Status of Women Is Associated with the Iron Concentration of Potable Groundwater in Rural Bangladesh. J Nutr, 141, 944-949. 